\title{
Process limits in high performance peel grinding of hardened steel components with coarse CBN grinding wheels Berend Denkena $^{\mathrm{a}}$, Alexander Kroedel ${ }^{\mathrm{a}}$, Michael Wilckens ${ }^{\mathrm{a}}$
}

\author{
aInstitute of Production Engineering and Machine Tools, Leibniz University Hannover, An der Universität 2, 30823 Garbsen, \\ Germany \\ * Corresponding author. Tel.: +49-511-762-5940; Fax: +49-511-762-5115. E-mail address: wilckens@ifw.uni-hannover.de
}

\section{$\underline{\text { Abstract }}$}

Recent developments in the production processes for cubic boron nitride (CBN) abrasive grains have led to commercially available grain sizes larger than $\mathrm{I}_{g}>300 \mu \mathrm{m}$. These superabrasive grains allow higher material removal rates during grinding of hardened steel components. Currently, these components are pre-machined by turning processes before being hardened and eventually finished by grinding. However, the turning process can be substituted by grinding with coarse CBN-grains since higher depths of cut are achievable when machining hardened components. This paper investigates the process behaviour of vitrified and electroplated grinding wheels with large grain sizes during the machining of hardened steel components. Process forces, wear behaviour and workpiece surface roughness are investigated for three different grain sizes and the process limits of both bond types are examined.

The investigations show that the vitrified tools do not fully suit the demands for peel grinding process with very high material removal rates since wear by means of bond breakage occurs. The electroplated tools on the other hand are capable of very high material removal rates. Their wear behaviour is characterized by clogging of the chip space if the process limit is reached. Even so, both tools outperform a standard hard-turning process in terms of process time by $74 \%$ and $94 \%$ respectively.

\section{Keywords}

CBN, grinding, high performance cutting, wear

\section{Funding}

By the Federal Ministry for Economic Affairs and Energy (BMWi) of Germany for the project "Resource efficient and productive grinding with coarse CBN" with the funding number "IGF 20042 N/1".

\section{Conflicts of interest/Competing interests}

The Authors declare that they have no conflict of interest.

\section{Availability of data and material}

- Not applicable -

$\underline{\text { Code availability }}$

- Not applicable -

\section{Authors' contributions}

Prof. Dr.-Ing. B. Denkena was responsible for funding acquisition and project administration and reviewed and edited the article together with Dr.-Ing. A. Krödel-Worbes in the writing process.

Dr.-Ing. A. Krödel-Worbes supervised the project.

M. Wilckens conducted the experiments, analysed the data and wrote the manuscript. 


\section{Introduction}

With regards to the advances in e-mobility, production processes need to be adapted to the new requirements regarding productivity, surface quality and energy efficiency. Especially the upcoming goal to reduce environmental impacts of the production process aggravates the call for a higher process efficiency . Grinding is widely known as a finishing operation with low material removal rates. Due to increasing demands on quality and process efficiency, the grinding technology is under high pressure to optimize machine tools, tools, and processes [1, 2]. These improvements have led to grinding processes that are no longer limited to finishing operations [3]. Exemplarily, high efficiency deep grinding (HEDG) uses high cutting speeds of $\mathrm{V}_{\mathrm{c}}>80 \mathrm{~m} / \mathrm{s}$ in combination with high depths of cut of $a_{e}>0.3 \mathrm{~mm}$ in order to achieve high removal rates $[4,5]$.

In order to withstand the high grain loads during processes with high material removal rates, the superabrasives cubic boron nitride (CBN) and diamond are used predominantly. With its high thermal, mechanical. and chemical stability, $\mathrm{CBN}$ is especially suitable for the machining of steel [6]. Contrary to diamond grains, CBN does not interact chemically with iron during the machining of steel and thus does not underly chemical wear. Therefore, many investigations focus on increasing the productivity of grinding processes with CBN tools [3, 7-9]. The used grains influence the efficiency of material removal significantly. Their size is of special importance as larger grains increase the tools chip space and grain protrusion. Therefore, very coarse diamond grains of diameters up to $\mathrm{d}_{\mathrm{g}}=800 \mu \mathrm{m}$ are used in construction or dismantling of large structures for abrasive cutting with high removal rates $[10,11]$. Until recently, CBN grains of diameters larger than $\mathrm{d}_{\mathrm{g}}>300 \mu \mathrm{m}$ have not been commercially available. However, this changed due to advances in process control during the crystallisation of coarse CBN grains with diameters of up to B602. Since their availability, no scientific investigations into their efficiency for rough grinding processes have been conducted. Preliminary investigations have proven, however, that the achievable material removal rates in hard grinding are higher than in hard turning [12].

The high material removal rates lead to high grain loads. Shi showed that the main cause for
CBN tool wear is friction [13], while Zhao devided the wear for finer grains into macro and micro fractures over the course of the tool life [14]. Naskar additionally identified thermal shock as a prime cause for the macro grain fracture for B150 grits[15].

From the above discussed literature, it becomes evident that a substantial amount of research has been conducted on CBN grinding tools. However, no investigations into the application and wear behaviour of very coarse grains $\left(d_{g}>300 \mu \mathrm{m}\right)$ have been presented. The change in surface area to grain volume for coarser grains influences grain retention forces and high grain engagements increase the grain load during the process. The resulting process and wear behaviour of these tools are yet unknown and will be investigated in this paper.

\section{Materials and Methods}

\section{Experimental Setup}

In this paper, six different grinding tools are used to machine hardened $100 \mathrm{Cr} 6$ steel shafts with a diameter of $\mathrm{dw}=60 \mathrm{~mm}$, a length of $\mathrm{dw}=300 \mathrm{~mm}$ and a Rockwell hardness of 55 HRC on a Schaudt CR41 cylindrical grinding machine with Castrol Variocut G 600 as coolant lubricant $(\mathrm{CL})$.

The used experimental setup is shown in Fig. 1 . The shaft is fixed in between centres and driven by the workpiece spindle, which enables a maximum rotational speed of $\mathrm{n}_{\mathrm{w}, \max }=1.000 \mathrm{rpm}$ and a maximum torque of $M_{w, \max }=48 \mathrm{Nm}$. Process forces are measured by two Kistler piezoelectrical dynamometers that were mounted within the flow of force on both clamping points and averaged. The grinding wheel is driven by the tool spindle with a maximum output of $\mathrm{PS}_{\mathrm{s} \text { max }}=43 \mathrm{~kW}$ at a maximum rotational speed of $\mathrm{ns, \operatorname {max }}=6.000 \mathrm{rpm}$. All grinding operations are carried out in a peel grinding process. The full depth of cut is removed in one pass with an angled tool profile that will be explained in detail further down. 


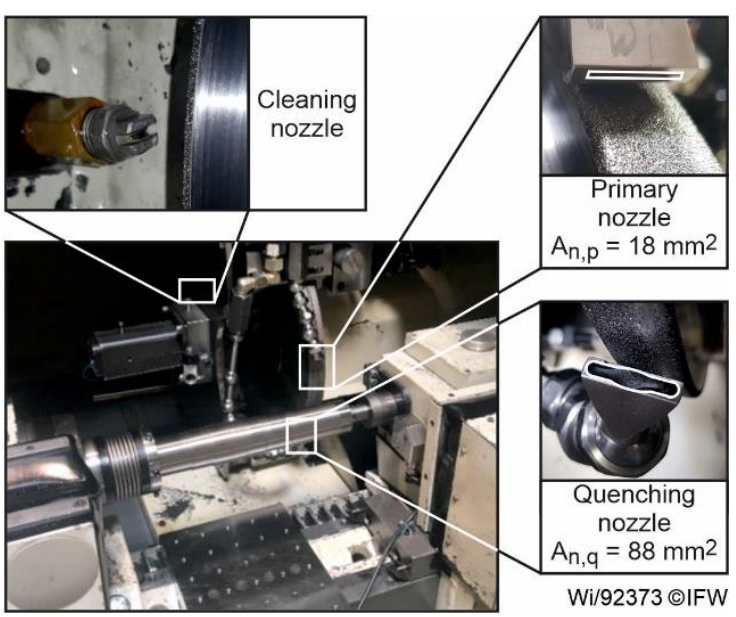

Fig. 1: Experimental setup

A dressing spindle with a maximum rotational speed of $n_{d, \max }=10.000 \mathrm{rpm}$ is mounted on the base of the machine bed in order to profile and condition the vitrified grinding tools. The attached diamond dressing roller has a diameter of $d_{d}=100 \mathrm{~mm}$ and a dressing width of $b_{d}=0,8 \mathrm{~mm}$. Due to the maximum rotational speed of the dressing spindle, the dressing speed was reduced to $v_{c d}=65 \mathrm{~m} / \mathrm{s}$ in order to ensure a dressing speed ratio of $q_{d}=0,8$. All tools were dressed with an overlapping rate of $U_{d}=6$ and a single depth of engagement of $a_{\text {ed }}=5 \mu \mathrm{m}$ until the entire tool was re-profiled.

In order to cool and lubricate the process, three coolant nozzles are used simultaneously. Two nozzles are supplied by the same CL-supply pump. The coolant flow is split between both nozzles equally. In order to generate varying flow properties, the outlet profile of the nozzles is altered to ensure high velocity on the primary nozzle and a high flow rate on the quenching nozzle (see Fig. 1,right). The primary nozzle supplies the coolant in cutting direction with a fluid velocity of $V_{C L}=50 \mathrm{~m} / \mathrm{s}$. The quenching nozzle is positioned below the contact area to cool the shaft and quench sparking chips. Additionally, a cleaning nozzle is set behind the grinding wheel, which delivers $\mathrm{CL}$ from an additional high pressure pump at a pressure of $p_{\mathrm{cl}}=25$ bar to clean the grinding tool from adhesions. Over all three nozzles, a cumulative flow of $Q_{C L}=130 \mathrm{l} / \mathrm{min}$ is delivered.

\section{Tools}

During the investigations presented in this paper, vitrified and electroplated tools were used in three grain sizes (B252, B427, B602) and their suitability and process limitations were compared. All six tools are designed with a diameter of $d_{s}=440 \mathrm{~mm}$. For the used roughing process, high grain retention forces are required to withstand the grain load during the grinding process. On the one hand, electroplated tools are known for high retention forces and high grain protrusion resulting in large chip spaces and large possible chip thicknesses. But these tools are expensive and cannot be dressed. On the other hand, vitrified tools are initially more cost efficient and can be dressed due to their structure with multiple layers of grains. Additionally, the vitrified bond can be designed to match the application regarding the desired bond properties. However, these tools show lower grain retention forces and higher profile wear than electroplated tools. For these investigations, Hermes Schleifmittel $\mathrm{GmbH}$ used their toughest available vitrified bond to manufacture all three tools. The electroplated tools were produced by the Günther Effgen $\mathrm{GmbH}$.

The electroplated tools are pre-profiled before plating and keep their profile throughout the investigations, while the vitrified tools are profiled before every experiment in order to ensure constant cutting conditions. The geometry of the tools is depicted in Fig. 2. It features an angled roughing section and a cylindrical finishing section. The roughing angle is $\alpha_{r}=12^{\circ}$ in feed direction. Due to this profile, the specific material removal rate is solely dependent on the used feed, which is shown in detail in Fig. 2. Due to the roughing angle, an increased depth of cut $a_{e}$ (Fig. 2, bottom) also increases the width of contact $b_{\text {eff }}$ of the grinding wheel. For additional clarification equations 1-3 calculate the specific MRR for peel grinding. It can be seen that the material removal rate per width of active grinding wheel profile beff is constant for varying depths of cut ae.

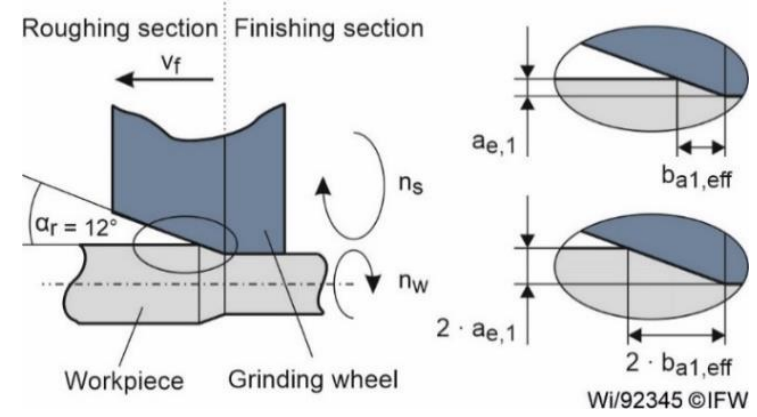

Fig. 2: Grinding tool geometry and the influence of the depth of cut on the specific material removal rate

$Q^{\prime}{ }_{w}=\frac{Q_{w}}{b_{\text {eff }}}=\frac{\pi \cdot d_{w} \cdot n_{w} \cdot \mathrm{f} \cdot \tan \alpha}{60}$

With $Q_{w}=\frac{\pi \cdot d_{w} \cdot n_{w} \cdot \mathrm{f} \cdot a_{e}}{60}$

and $a_{e}=b_{e f f} \cdot \tan \alpha$ 
The generated chips were collected after each experiment and evaluated with a Keyence VHS 600 DSO digital microscope. The length of the chips was then measured and their overall appearance compared in order to evaluate different chip formation mechanisms.

\section{Process Parameters}

All experimental investigations were carried out with constant process parameters according to Table 1. The feeds were varied for both bond types in five steps within the noted range. Each experiment was repeated once. The process forces as well as the wear behaviour and the surface roughness of the machined shafts were measured during the investigations. The roughness was measured on five different positions along the shaft's circumference.

Table 1:Process parameters for the experimental investigations

\begin{tabular}{c|cc}
\hline PROCESS & ELECTRO- & VITRIFIED \\
\hline PARAMETER & PLATED & CITA \\
\hline $\begin{array}{c}\text { Cutting speed } \\
\mathrm{V}_{\mathrm{c}}[\mathrm{m} / \mathrm{s}]\end{array}$ & 100 & 100 \\
$\begin{array}{c}\text { Depth of cut } \\
\text { ae }[\mu \mathrm{m}]\end{array}$ & 500 & 500 \\
$\begin{array}{c}\text { Speed ratio } \\
\text { q [-] }\end{array}$ & 70 & 70 \\
$\begin{array}{c}\text { Feed } \mathrm{f} \\
{[\mathrm{mm} / \mathrm{rev}]}\end{array}$ & $0.3-1.8$ & $0.3-0.6$ \\
\hline
\end{tabular}

This paper will present the scientific results of the process behaviour of three vitrified and three electroplated grinding wheels. For each bond type the results of process forces, wear behaviour, and surface roughness are considered separately. After the individual results, the tool concepts will be compared in all three areas and their process limits and industrial applications will be discussed.

\section{Results and discussion \\ 3.1 Vitrified grinding wheels \\ 3.1.1 Process forces}

Fig. 3 shows the process forces for different feeds for all three vitrified tools. Overall, the process normal forces are increasing with higher feeds. The B252 tool results in the highest process forces, followed by the $\mathrm{B} 602$ and B427 tool. The process normal forces for the B252 and B602 tool increase linearly over the investigated feeds. For the B252 tool the forces increase from $F_{n, 0.3}=115 \mathrm{~N}$ to $F_{n, 0.6}=193 \mathrm{~N}$, which converts to a force increase of $260 \mathrm{~N}$ per $\mathrm{mm}$ feed within the investigated feed range. The process normal forces for the $\mathrm{B} 602$ tool rises with a rate of $193 \mathrm{~N}$ per $\mathrm{mm}$ feed from $\mathrm{F}_{\mathrm{n}, 0.3}=95 \mathrm{~N}$ to $F_{n, 0.6}=153 \mathrm{~N}$. Not only are the overall forces of the coarser tool lower by $18 \%$, but the force increase per $\mathrm{mm}$ feed is also lower by about $28 \%$. The overall force increase results from higher grain loads due to the increasing chip thickness at higher feeds. The lower overall forces for coarser grains derive from the decreasing number of individual grains in the contact area. Over increasing feeds this effect is magnified as the number of engaged grains is higher for smaller grains and therefore the accumulated forces increase more significantly even though the chip thickness at each grain is lower.

Contrary to the force development of the B252 and B602 tools, the normal force for the B427 tool increases irregularly. For feeds of $0.3<\mathrm{f} \leq 0.5 \mathrm{~mm}$ the process forces increase gradually but at a $54 \%$ lower level of process forces than that of the B252 tool. At a feed of $f=0.55 \mathrm{~mm}$ the normal force decreases while the process tangential force increases. The reason for this change in force development can be explained with the B427 tool's wear behaviour and the tool's geometry. Even though the tool uses the same bond composition as the other two tools, this tool wears more severely. This influences the tool's geometry and leads to a reduced width of the finishing section. The purpose of the finishing section is, however, to flatten the roughness peaks on the surface of the workpiece. During this process, very little material is removed. Thus, the material removal process of the finishing section is very inefficient and results in high friction, which is represented by a higher share of normal forces. At a feed of $f=0.55 \mathrm{~mm}$, the finishing section of the tool breaks off. Consequently, the depth of cut and the width of the finishing section are reduced. This in turn decreases the process normal forces. Furthermore, the surface roughness significantly increases due to missing finishing section as shown in the following chapters. The process tangential forces also increase due to the change in the tool geometry. With the reduction of the finishing width, the width of the roughing section increases. This leads to a growing number of active grains with significant amounts of material removal, that is represented by a higher share of tangential force components. Thus, the process tangential forces increase. 
At a feed of $f=0.6 \mathrm{~mm}$ the tool wears accordingly while a further increase of the feed does not cause more severe wear.

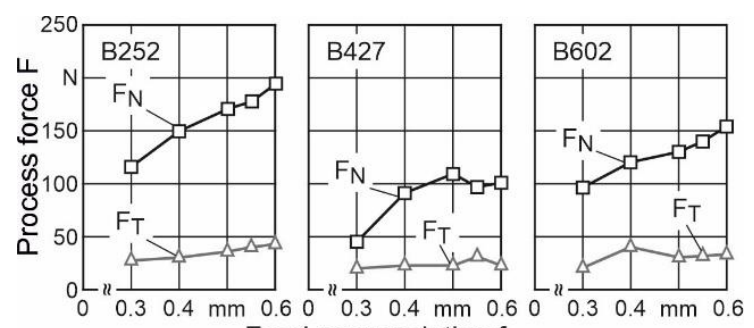
Feed per revolution $f$

\begin{tabular}{lll}
\hline Process & Grinding tool & Cooling \\
parameters & B252, B427, B602 & Castrol \\
$\mathrm{v}_{\mathrm{C}}=100 \mathrm{~m} / \mathrm{s}$ & Bond: vitrified & Variocut G 600 \\
$\mathrm{q}=70$ & Workpiece & Three coolant \\
$\mathrm{f}=0.3-0.6 \mathrm{~mm}$ & 100Cr6, HRC 55 & nozzles \\
$\mathrm{a}_{\mathrm{e}}=500 \mu \mathrm{m}$ & &
\end{tabular}

Fig. 3: Process forces for vitrified tools at increasing feeds

\subsubsection{Wear behaviour}

To understand the process forces in more detail, the wear behaviour of the vitrified tools is investigated. Fig. 4 (top) shows the initial and worn state of the vitrified tools after a removed volume of $V=18,500 \mathrm{~mm}^{3}$ with a depth of cut of $a_{e}=0.5 \mathrm{~mm}$ and $a$ feed of $f=0.3 \mathrm{~mm} / \mathrm{rev}$.

The dotted white line in the top pictures of the dressed tool indicates the edge between the roughing and finishing section. This line is also depicted in the pictures of the worn tools to clarify the changes due to wear resulting from mechanical overload. To make the macro wear of the tool's profile visible and to show that the bond breakage is evident over the entire circumference of the tools, the pictures of the worn tools are taken while the tool is rotating. The worn tools (Fig. 4, top middle and right) show two different wear behaviours depending on the amount of broken bond in the contact area.

The B252 and B602 tool show a partial breakout of the contact area since the load on the bond is highest at the boundary between the two sections. This area breaks first, which can be observed by the appearance of the two refraction lines to the left and right of the original boundary indicated by the dotted white line. The distance between both lines indicates the width of the tool wear. The used bond for these tools therefore was not hard enough to withstand the high process forces and grains broke out continually. As a result, new sharp grains are exposed and engage with the workpiece. This leads to fewer grains with larger grain protrusion in the contact area and thus lower process forces.

The wear behaviour of the B427 tool on the other hand was more rapid as the bond broke over the entire contact area of the tool (Fig. 4, top right). This includes the area of the roughing section that was in contact with the workpiece and the finishing section of the tool. This is shown in the picture by a single refraction line that was shifted in feed direction from the original line between roughing and finishing section (dotted white line). In this case entire parts of the bond break from the tool reducing the depth of cut and thereby the measured process forces, as is seen in Fig. 3 (B427) in decreasing forces for higher feeds.

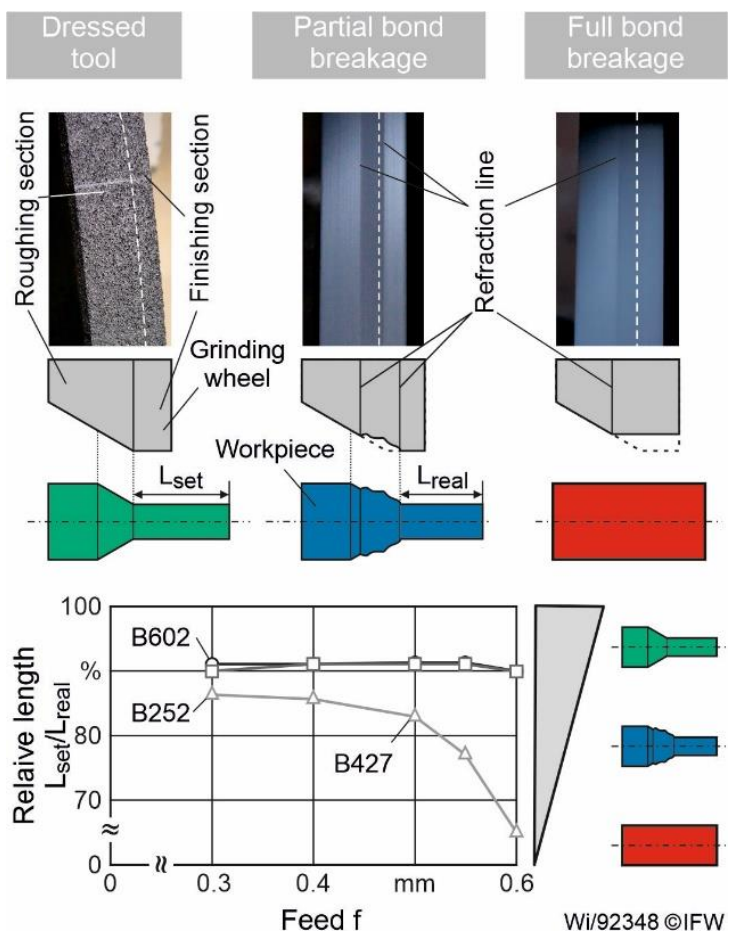

Fig. 4: Wear mechanisms of vitrified tools and their effect on the workpiece

The profile wear of the tools can additionally be measured by the machined length on the shaft. This length is equal to the length set in the NCcode for an unworn tool. As the boundary between roughing and finishing section wears (Fig. 4, top middle), the width of the finishing section shrinks. This reduces the machined length of shaft Lreal in relation to the pre-set length $L_{\text {set. }}$ On the bottom of Fig. 4, the ratio of $L_{\text {real }} / L_{\text {set }}$ is shown for all three grain sizes over the investigated feeds. As discussed before, the B252 and B602 tools show partial breakouts for all feeds which reduces the machined lengh $L_{\text {real }}$ by constant $10 \%$ for all feeds. The B427 tool on the other hand wears more severely and the 
machined workpiece area decreases for growing feeds.

The effect of the bond failure can be seen in the process forces as well as in the surface roughness of the machined parts. Fig. 5 shows the process forces during an experiment when the B427 tool's bond broke over the entire contact area and a picture of the corresponding machined shaft. It can be seen that at the beginning of the process, the forces decrease slowly as the bond begins to break and new, sharp grains engage the workpiece as was explained for the B252 and B602 tools. In this case, however, the rest of the bond breaks suddenly at about $t=19 \mathrm{~s}$. This is confirmed by a sudden drop in the process normal and tangential forces as the reduction of the outer diameter of the tool leads to lower material removal and thus lower process forces. Additionally, the shifted refraction line in the picture on the right shows the aforementioned wear characteristic of the B427 tool.

The increased surface roughness $(R z=70 \mu \mathrm{m}$ compared to $R z=15 \mu \mathrm{m}$ ) on the machined shaft is even visible to the naked eye. After the initial dressing, the tool topography is smoothed with low variance in grain protrusion. The dressed finishing section therefore produces a low surface roughness. As large areas of bond break away from the tool, the finishing section shrinks and ultimately disappears entirely. This leads a reduction of the smoothing of peaks which increases the resulting surface roughness (Fig. 5, top).

As both, the $\mathrm{B} 602$ and $\mathrm{B} 252$ tool, wear less than the B427 tool it is evident that this grain size is not recommendable for the used bond type. Since the smaller B252 grains have a better grain surface to volume ratio, the grain retention forces for this tool are higher. The B602 tool on the other hand offers high grain protrusion and low process forces due to increased chip thickness. Reduced grain retention forces in comparison to the $\mathrm{B} 252$ tool and higher process forces in relation to the $\mathrm{B} 602$ tool causes increased wear on the B427 tool.

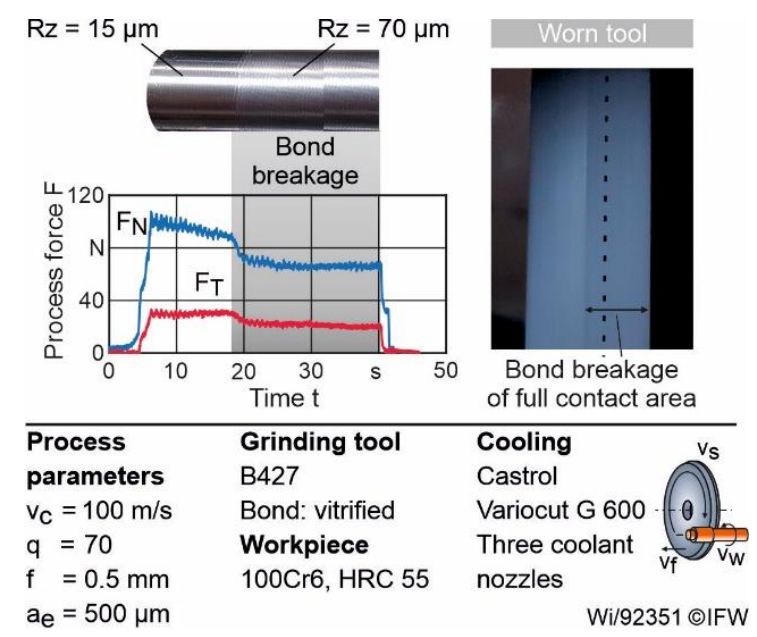

Fig. 5: Effect of the bond breakage of the B427 vitrified tool on the process forces

\subsubsection{Surface roughness}

The presented tools are designed for rough grinding which, in a production environment, is followed by finishing operations. Therefore, the generated roughnesses need to be lower than the depth of cut during finishing but is otherwise of secondary importance. In order to assess the application behaviour of the investigated tools holistically, the measured roughness valures for the vitrified tools are show in Fig. 6 regarding different grain sizes and feed rates.

In accordance with the process forces, the B252 and B602 tools can be grouped together, while the results from the B427 tool differ from them. The surface roughness of the first two tools shows little influence of grain size and process parameters. Both tools show an average roughness over all feeds of $R_{B B 252}=4.25 \mu \mathrm{m}$ and $R_{\mathrm{B} 602}=4.97 \mu \mathrm{m}$ with a mean roughness deviation of $\mathrm{Ra}_{\mathrm{B} 252}=0.52 \mu \mathrm{m}$ and Raв602 $=0.69 \mu \mathrm{m}$. This can be charged to the fact, that all tools were dressed equally, resulting in equal topographies of the grinding tools. The finishing section of the tools generates the final surface roughness of the workpiece. Additionally, the dressing process reduces the differences in grain heights equally for all grain sizes. With the used axial feed, the finishing section smoothes the surface similar to a spark out process. This effect intensifies with an increasing width of the finishing section. This is also evident in Fig. 6 as the resulting surface roughnesses of the B252 and B602 tool show to be independent of grain size and feed. The B427 tool shows a different behaviour. Firstly, the surface roughness at the lowest feed of $f=0.3 \mathrm{~mm}$ is already about $70 \%$ higher as the B252 and continues to rise from this value. In 
correlation with the lower process normal forces (Fig. 3) the presented roughness values rise significantly. This behaviour is explained by the wear behaviour of this tool. With the wear of the finishing section, the number of active grains is reduced. This leads to an increase in chip thickness, thereby resulting in higher surface roughnesses. Additionally, the reduction of finishing width reduces the spark out effect mentioned earlier and intensifies this effect.

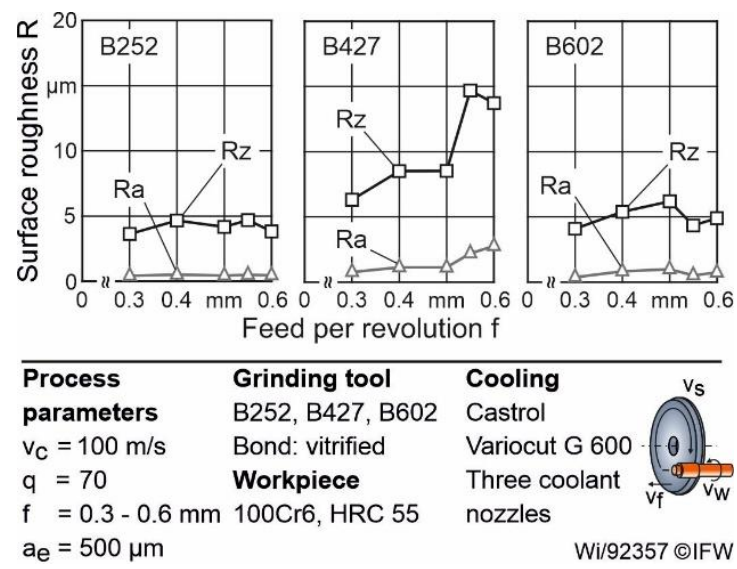

Fig. 6: Surface roughness for vitrified tools of different grain sizes

\subsection{Electroplated tools \\ 3.2.1 Process forces}

Fig. 7 shows the process forces for different feeds for all three electroplated tools. As the wear behaviour of the electroplated tools is different to the vitrified tools, the process forces grow differently. For this bond, all process forces are increasing with rising feeds and decreasing with growing grains. When using the B252 tool, the process normal force increases over the investigated feeds from $\mathrm{F}_{\mathrm{N}, 0.3}=155 \mathrm{~N}$ to $\mathrm{F}_{\mathrm{N}, 1.8}=1.473 \mathrm{~N}$.

For the B427 and B602 tool, the process normal forces increase linearly from $\mathrm{F}_{\mathrm{N}, 0.3}=135 \mathrm{~N}$ to $\mathrm{F}_{\mathrm{N}, 1.8}=377 \mathrm{~N}(\mathrm{~B} 427)$ and from $\mathrm{F}_{\mathrm{N}, 0.3}=119 \mathrm{~N}$ to $F_{N, 1.8}=318 N$ (B602) respectively. The force developments equal a normal force increase of $160 \mathrm{~N}$ per $\mathrm{mm}$ feed (B427) and $133 \mathrm{~N}$ per $\mathrm{mm}$ feed (B602). As shown for the vitrified tools, the process (normal) forces are not only lower by about $13 \%$ but also grow $17 \%$ slower for the coarser B602 grains. The lower overall forces result from the reduction of active grains in the contact area. The load on the individual grain is magnified by growing chip thicknesses. Fewer active grains with higher chip thicknesses and thereby higher loads lead to an overall reduction of process forces, leading to a more efficient material removal. The force development for the
B252 tool differs significantly from that of coarser grain tools. When using the B252 tool, the process normal force increases exponentially over the investigated feeds from $\mathrm{F}_{\mathrm{N}, 0.3}=155 \mathrm{~N}$ to $\mathrm{F}_{\mathrm{N}, 1.8}=1.473 \mathrm{~N}$. While the higher (normal) forces can be explained as mentioned above, the exponential force development results from material adhesions to the tool, which will be further explained in the following chapter.

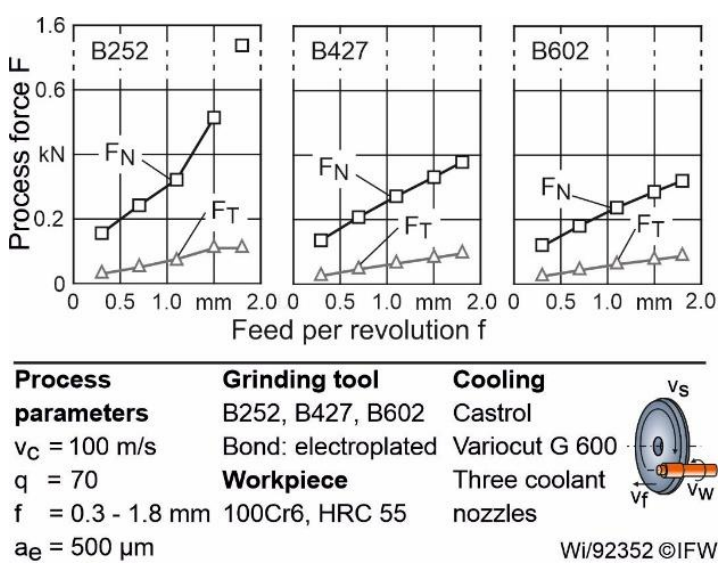

Fig. 7: Process forces for electroplated tools at increasing feeds

\subsubsection{Wear behaviour}

Electroplated tools consist of a single layer of abrasive grains. As soon as this layer is worn or broken, the tool can no longer be used. Dressing to expose new grains is not possible. The exponential increase in process normal forces for the B252 electroplated tool, shown in Fig. 7, is credited to the clogging of this tool. Fig. 8 shows all three electroplated tools in their initial state (left) and their worn state (right) after using a depth of cut of $a_{e}=500 \mu \mathrm{m}$ and a feed of $\mathrm{f}=1.8 \mathrm{~mm} / \mathrm{rev}$ for $V_{w}=18,500 \mathrm{~mm}^{3}$. The B252 tool shows severe clogging to a point where the grains are entirely covered and no grain protrusion or chip space is left. Over the investigations, the increasing amount of clogged material leads to further rubbing on the workpiece resulting in exponentially growing process normal forces and temperatures. On the left of the worn state picture of the B252 tool, the grains are covered by adhering material and rubbing marks can be seen.

The used B427 tool (Fig. 8, middle right) also shows adhering material within the chip space. In contrast to the B252 tool, this material does not cover any of the grains. Consequently, it does not hinder the contact between the grains and the workpiece and thereby the material removal. 
For the coarser B602 tool (Fig. 8, bottom) clogging or even adhering material was not observed. After cleaning the clogging from the tools with mechanical sharpening, the CBN grains themselves on all three tools were not visibly affected and still show sharp and unbroken cutting edges.

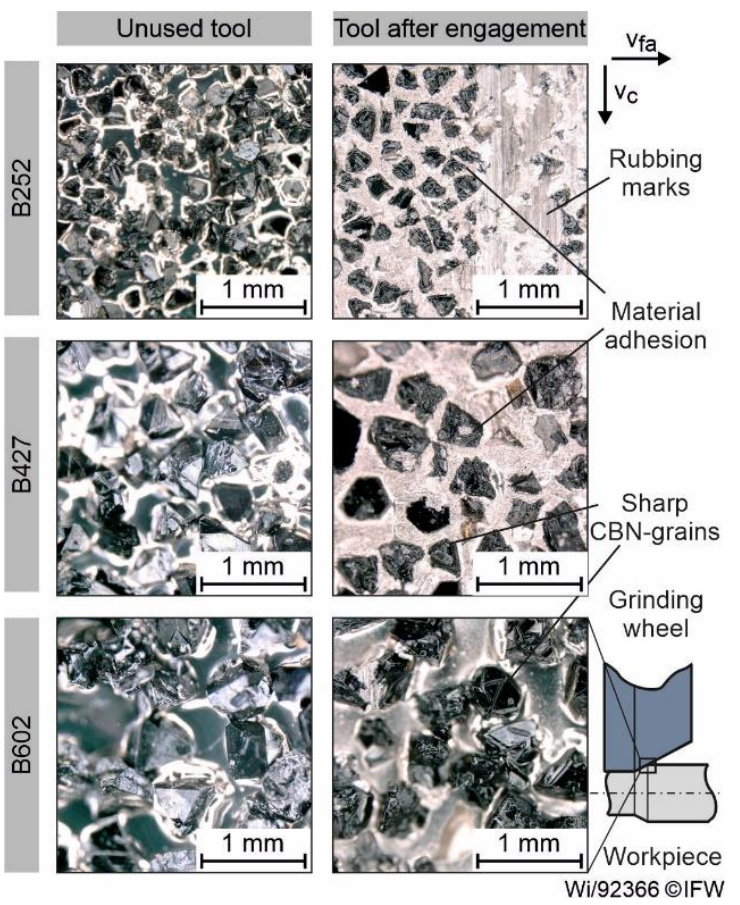

Fig. 8: Initial and worn state of electroplated tools

The effect of material adhesion and clogging of the B252 tool is shown in Fig. 9. The measured process forces during the process are depicted on the left, while the clogged tool is visible on the right of the figure. Over the duration of the grinding process the forces grow continually. As explained before, this happens due to increasing amounts of material adhesion to the abrasive layer of the tool. The adhering material hinders the efficient removal of material and leads to the clogging of the chip space. Without sufficient chip space, the amount of coolant to the contact area is reduced as well as the chip removal from the contact area impeded. The adhering material leads to decreasing material removal efficiency, higher contact area temperatures and more material adhesion. After the process, the clogging was visible along the entire circumference of the tool as can be seen on the right side of Fig. 9.

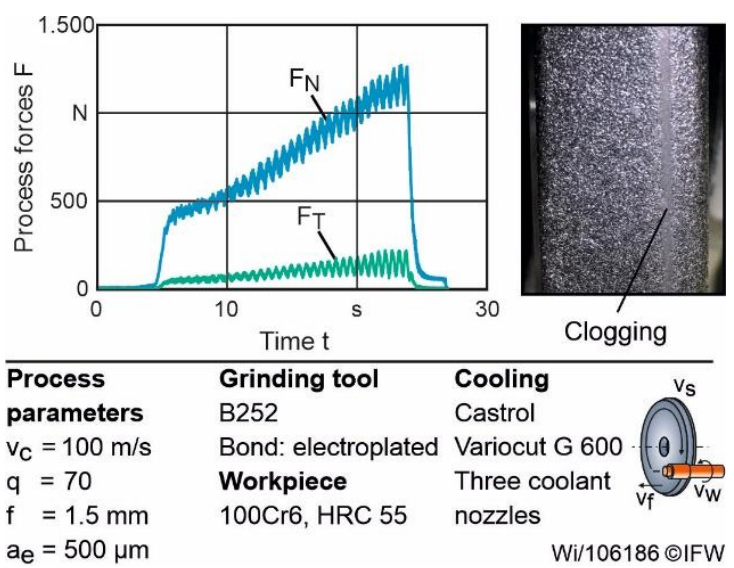

Fig. 9: Increasing process forces as a result of material adhesion
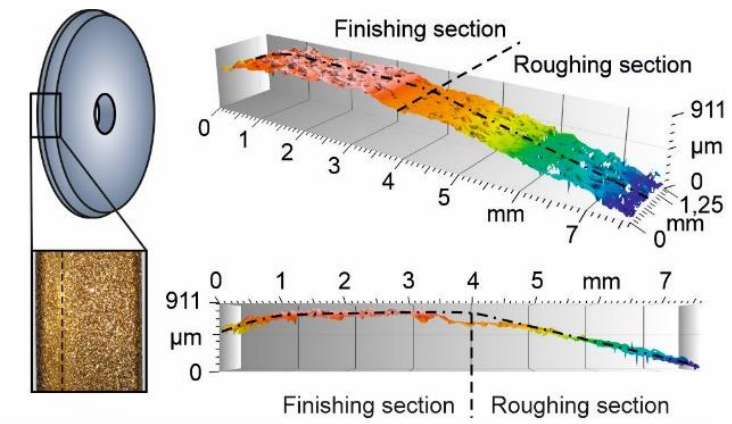

\begin{tabular}{lll}
\hline Process & Grinding tool & Cooling \\
parameters & B252 & Castrol \\
$\mathrm{v}_{\mathrm{C}}=100 \mathrm{~m} / \mathrm{s}$ & Bond: electroplated & Variocut G 600 \\
$\mathrm{q}=70$ & Workpiece & Three coolant \\
$\mathrm{f}=1.8 \mathrm{~mm}$ & 100Cr6, HRC 55 & nozzles \\
$\mathrm{a}_{\mathrm{e}}=500 \mu \mathrm{m}$ & &
\end{tabular}

Fig. 10: 3D-image of the worn B252 tool's topography

To visualize the tool's wear further, a segment of the tool was cut out and a 3D scan was generated with a Confovis Duo Vario which uses optical focus variation. The resulting scan is shown in Fig. 10. Apart from the visible wear by material adhesion, the scan reveals profile wear along the border between the two sections of the tool. This indicates that the tool was not only worn by clogging but also by breaking (out) of abrasive grains. This loss of grains leads to rubbing of the workpiece with the base body of the tool, which results in a similar wear behaviour as was seen using the vitrified tools. Whereas the vitrified bond broke to reveal new, sharp grains, the same behaviour for electroplated tools leads to fewer cutting grains in the roughing section. Therefore, the material removal is no longer performed in this section but rather at the finishing section, eliminating the benefits of the tools profile. With this profile loss, the tools can no longer be used and have to be re-plated. To conclude, the wear behaviour of the electroplated tools is dominated by material adhesion and the 
clogging of the chip space, which ultimately leads to the elimination of the grain protrusion and, in combination with high process forces, leads to profile wear that renders the tools unfit for further use. Also, the wear is significantly lowered by the use of larger grains. The larger chip space of the coarser tools provides sufficient space for a coolant supply and a chip removal from the contact area.

\subsubsection{Surface roughness}

The electroplated tools were not dressed in the course of these investigations. Therefore, the resulting surface roughnesses shown in Fig. 11 are as expected higher than for the vitrified tools. For all grain sizes, the surface roughness of the workpiece increases with rising feeds and larger abrasive grains. This is credited to the rising chip thickness. As was observed for the process forces, the wear behaviour of the B252 tool sets the development of surface roughnesses off in comparison to the coarser grains. Starting at an average roughness of Rzв252,0.3 $=20 \mu \mathrm{m}$ it rises increasingly exponentially in accordance to the clogging tool. For feeds of $0.3 \mathrm{~mm}<\mathrm{f} \leq 1.1 \mathrm{~mm}$ the roughness rises linearly and by a small amount. The first material adhesions lead to the levelling of single grain groves resulting in a lower increase of the roughness as for the coarser grains. As the roughing section of the tool wears at feeds larger than $f>1.1 \mathrm{~mm}$ and grains begin to break out, the number of active cutting edges is reduced. This leads to higher chip thicknesses, which results in an increased surface roughness.

The B427 and B602 tools behave differently as they do not wear as the B252 tool and the grain protrusion is not eliminated fully during the investigations. The displayed average surface roughness starts at $\mathrm{RzB} 427,0.3=31 \mu \mathrm{m}$ and $\mathrm{Rz}_{\mathrm{B} 602,0.3}=34 \mu \mathrm{m}$ and increases linearly over the investigated feeds. This linear trend for the B427 tool discontinues at a feed of $f=1.8 \mathrm{~mm}$ as the surface roughness ( $\left.R z_{B 427,1.8}=48 \mu \mathrm{m}\right)$ is at about the same level as at a feed of $f=1.5 \mathrm{~mm}\left(R_{B} 427,1.5=31 \mu \mathrm{m}\right)$. Considering the microscopic images in Fig. 8, the elimination of the tool's chip space visibly reduces the surface roughness by levelling roughness peaks. The B602 tool on the other hand results in an average surface roughness of $\mathrm{Rz}_{\mathrm{B} 602,1.8}=55 \mu \mathrm{m}$ at the highest feed. As there were no visible material adhesions and no deviations in the process forces it remains to be mentioned that this is below the allowance for a following finishing operation in an industrial application of about $a_{e}$, finish $=100-300 \mu \mathrm{m}$.

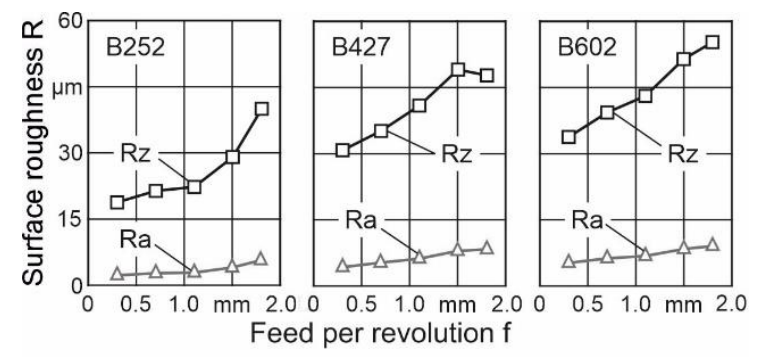

\begin{tabular}{lll}
\hline Process & Grinding tool & Cooling \\
parameters & B252, B427, B602 & Castrol \\
$\mathrm{v}_{\mathrm{C}}=100 \mathrm{~m} / \mathrm{s}$ & Bond: electroplated & Variocut G 600 \\
$\mathrm{q}=70$ & Workpiece & Three coolant \\
$\mathrm{f}=0.3-1.8 \mathrm{~mm}$ & 100Cr6, HRC 55 & nozzles \\
$\mathrm{a}_{\mathrm{e}}=500 \mu \mathrm{m}$ & &
\end{tabular}

Fig. 11: Surface roughness of electroplated tools for varying feeds

\subsubsection{Process limits}

After the investigations of the influence of the feed on the process forces and wear of all tools, this chapter focusses on process limits. The results of the wear behaviour of the vitrified tools show that their limit is already reached for all grain sizes as the tool breaks and thus can no longer remove the desired amount of material. Therefore, the electroplated tools are better suited for the rough grinding process presented in this paper. For these tools, the clogging of the B252 tool proves its overloading and the profile wear evidences that its performance limit is exceeded as well, while the coarse B602 tools shows insignificant amounts of material adhesion or wear. In order to determine the performance potential of these very coarse CBN grains for rough grinding, the investigated feeds were further increased until process limits are reached.

Fig. 12 shows the resulting process forces for increased feeds. As the feed is increased further than the previous range (grey background) by increments of $\Delta f=0.3 \mathrm{~mm}$, the process forces increase as expected. At a feed of $f=3.0 \mathrm{~mm}$ the process normal force rises drastically by about $100 \%$ in reference to a feed of $f=2.7 \mathrm{~mm}$. The slope of this rapid increase decreases with higher feeds and at a feed of $f=3.6 \mathrm{~mm}$ the process normal force is even reduced to the force value of a feed of $f=3.0 \mathrm{~mm}$. In order to understand this development, Fig. 12 shows the measured process forces over the duration of the process at a feed of $f=3.3 \mathrm{~mm}$. As the tool is in contact with the workpiece, the process normal force increases continually until about 12 seconds 
into the process. Furthermore, the process tangential force shows harmonics over the same time period. This change in the force development indicates a change of the tools geometry. The initial increase of the process normal force is very similar to the effect seen in the clogging of the B252 tool in Fig. 9 which is supported by the harmonics seen in the tangential force. They indicate the clogging of the tool while the breaking off of the harmonics of the tangential force and the end of the linear normal force increase marks the breaking out of grains from the B602 tool. This shows the similar wear behaviour of this tool compared to the B252 tool after an initial clogging of the tool by adhering material.
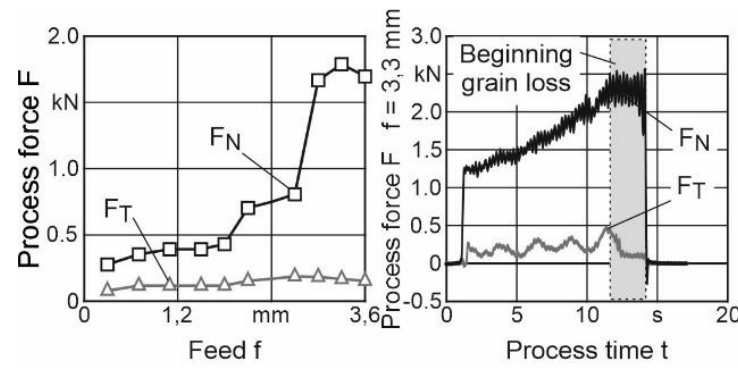

\begin{tabular}{llll}
\hline Process & Grinding tool & Cooling \\
parameters & B252, B427, B602 & Castrol \\
$\mathrm{v}_{\mathrm{C}}=100 \mathrm{~m} / \mathrm{s}$ & Bond: vitrified & Variocut G 600 \\
$\mathrm{q}=70$ & Workpiece & Three coolant \\
$\mathrm{f}=0.3-0,6 \mathrm{~mm}$ & 100Cr6, HRC 55 & nozzles \\
$a_{e}=500 \mu \mathrm{m}$ & & & Wi/92380 @IFW
\end{tabular}

Fig. 12: Process forces for increasing feeds in peel grinding

In order to visualize the wear of the B602 tool, a segment was cut out and a 3D-scan of its topography was created as was described for the B252 tool. The shown topography in Fig. 13 proves the aforementioned similarity in the wear behaviour. The breakage and loss of abrasive grains led to the depicted profile wear. The grains of the roughing section of the tool that have been in contact with the workpiece are worn which eliminates the purpose of the roughing section and leads to increasing process forces. To conclude the analysis into the process limit of the electroplated tools for rough grinding, it can be said that the wear is characterized by the same processes of clogging and profile loss for both B252 and B602 tools but at very different feeds. As electroplated tools are not dressed or cleaned in industrial process, the clogging limits the highest possible feed. As the clogging is indicated by escalating process forces, the process limit is set at one tested feed value lower. This brings the process limit for the B252 tool to a feed of $f_{B 252, \max }=0.7 \mathrm{~mm}$ and for the $\mathrm{B} 602$ to $\mathrm{f}_{\mathrm{B} 602, \max }=2.7 \mathrm{~mm}$ respectively.

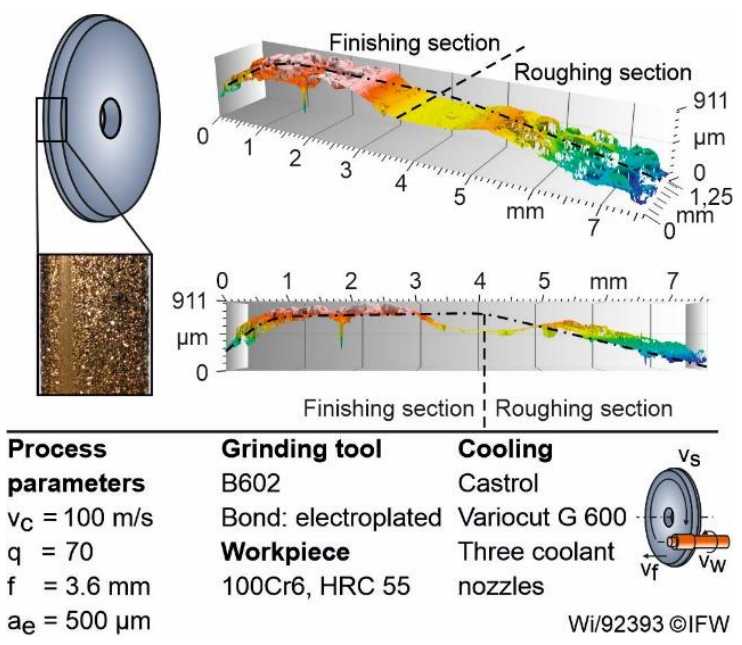

Fig. 13: 3D-image of the worn B602 tool's topography

\subsection{Field of application}

Both vitrified and electroplated tools are currently used for industrial grinding processes while no industrial process for $\mathrm{CBN}$ grains larger than $d_{g}=300 \mu \mathrm{m}$ is yet known for either bond system. To identify possible application areas both tools were referenced to an industrial turning process. A Seco DCMT11T304-F1 hard turning insert and the two B602 tools were used to remove $V_{W}=61.000 \mathrm{~mm}^{3}$ of a hardened $100 \mathrm{Cr} 6$ shaft. Fig. 14 shows the comparison of the resulting average surface roughness $R z$ on the left and process time t on the right.

The vitrified tool produces an average surface roughness of $R z_{\text {vit }}=4,9 \mu \mathrm{m}$, which is lower by $63 \%$ than the resulting average roughness of the turning process of $\mathrm{Rz}_{\text {turn }}=13.1 \mu \mathrm{m}$. The electroplated tool, on the other hand, increases the surface roughness to $R z_{\text {plated }}=55.1 \mu \mathrm{m}$, which equals a $420 \%$ rise in reference to the turning process. Roughing processes are always followed by finishing operations and all three depicted processes generate surface roughnesses that are lower than the finishing allowance, as was mentioned earlier. But it clarifies the differing workpiece surface properties that are achievable by coarse CBN grains.

On the right side of Fig. 14, the required process times are shown. Here, the benefit of the rough grinding process becomes evident. In reference to the process time in hard turning (turn $=251 \mathrm{~s}$ ), both grinding tools remove the desired material 
in shorter process times. The vitrified tool takes $t_{\text {vit }}=64 \mathrm{~s}$ at a feed of $f_{\text {vit,max }}=0.6 \mathrm{~mm}$ while the electroplated tool can reduce the process time even further to $t_{\text {plated }}=14 \mathrm{~s}$ due to the higher maximum feed of $f_{\text {plated, } \max }=2.7 \mathrm{~mm}$. The process time reductions equal $74 \%$ and $94 \%$ respectively in relation to the turning process. Due to the utilization of coarse CBN grains for the rough grinding operation, hardened steel components can be machined with a high productivity. Vitrified tools result in low average surface roughnesses while reducing the process time significantly. Electroplated tools reach three times higher material removal rates of Q'w $=650 \mathrm{~mm}^{3} / \mathrm{mm} \cdot \mathrm{s}$ but result in rougher surfaces.

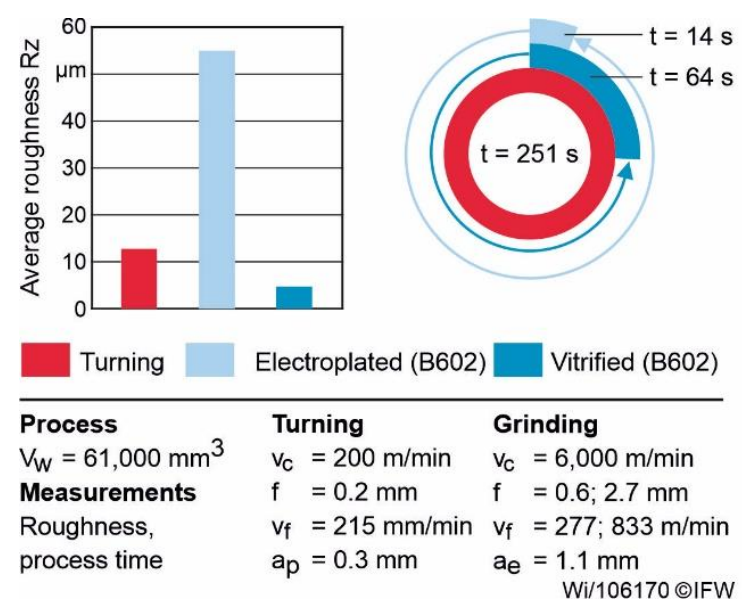

Fig. 14: Comparison of process time and surface roughness between rough grinding and turning

\section{Conclusion and Outlook}

The presented work shows the results from scientific investigations into the process and wear behaviour of electroplated and vitrified CBN grinding tools with coarse CBN grains $\left(d_{g}>300 \mu m\right)$ in a peel grinding process. After presenting the process forces, wear behaviour and resulting surface roughness for three grain sizes (B252, B427, and B602) the process limits for both bond types was discussed. Afterwards the performance of the process for both bond types was compared with a hard turning process of hardened $100 \mathrm{Cr} 6$ shafts. From this work, the following conclusions were drawn:

- $\quad$ The process forces for the vitrified B252 and B602 tool increase linearly with rising feeds. The process normal forces of the B252 tool are overall $18 \%$ higher and grow $28 \%$ faster than for the coarser B602 tool.

- The B427 tool shows fluctuating process forces as large areas of the bond break during the process, reducing the number of active grains and depth of cut.

- As the B427 possesses smaller chip spaces than the B602 tool and higher loads on the single grains than the $\mathrm{B} 252$ tool the bond breakage is more pronounced.

- Due to the wear of the vitrified tools, their process limit was reached at $\mathrm{f}=0.6 \mathrm{~mm}$ for the B252 and B602 tools, while the $B 427$ tool could not be used in the presented process.

- With progressing profile wear of the vitrified tools, the finishing section shrinks which increases tangential process forces and surface roughnesses.

- The electroplated tools were used at increased feeds of up to $f=1.8 \mathrm{~mm}$ which equals in rise in comparison to the vitrified tools of $\Delta f=300 \%$.

- The process forces for the electroplated tools increase linearly with rising feeds.

- The process normal forces of the B602 tool are overall $13 \%$ lower and grow slower by $17 \%$ than for the B427 tool.

- In case of the B252 tool the forces increase exponentially due to the clogging of the chip space at feeds of $\mathrm{f}>1.1 \mathrm{~mm}$. The B602 tool shows the same wear behaviour at feeds larger than $\mathrm{f}>2.7 \mathrm{~mm}$ which is considered the process limit for these tools.

- Additionally, the measured force signal shows signs of clogging as harmonics of the tangent force signal and grain breakage as a reduction of normal forces for these tools.

- To show the benefits of the hard grinding process with both bond types, a comparison with a hard turning process showed a possible reduction in process time of $74 \%$ for the vitrified tools and of $94 \%$ for the electroplated tools

The IFW continues the investigation into the application of coarse CBN grains. In addition to analysis into the chip formation and resulting chip dimensions, following scientific projects will focus on the application of coarse CBN grains in plunge grinding.

\section{Acknowledgement}

The authors would like to thank the Federal Ministry for Economic Affairs and Energy (BMWi) of Germany for their organizational and 
financial support within the project "Resource efficient and productive grinding with coarse CBN" with the funding number "IGF 20042 N/1".

\section{References}

[1] Caggiano A, Teti R. CBN Grinding Performance Improvement in Aircraft Engine Components Manufacture. Procedia CIRP 2013; 9: 109-14 [https://doi.org/10.1016/j.procir.2013.06.17 7]

[2] Rabiei F, Rahimi AR, Hadad MJ. Performance improvement of eco-friendly MQL technique by using hybrid nanofluid and ultrasonic-assisted grinding. The International Journal of Advanced Manufacturing Technology 2017; 93(1-4): 1001-15

[https://doi.org/10.1007/s00170-017-05219]

[3] Uhlmann E, Hochschild L. Tool optimization for high speed grinding. Production Engineering - Research and Development 2013; 7(2-3): 185-93 [https://doi.org/10.1007/s11740-013-04475]

[4] Klocke F, Barth S, Mattfeld P. High Performance Grinding. Procedia CIRP 2016; 46: 266-71 [https://doi.org/10.1016/j.procir.2016.04.06 7]

[5] Tawakoli T, Barrett CG. High efficiency deep grinding: Technology, process planning, and economic application. London: Mechanical Engineering Publications Limited 1993.

[6] Ichida Y, Fujimoto M, Inoue Y, Matsui K. Development of a High Performance Vitrified Grinding Wheel using UltrafineCrystalline cBN Abrasive Grains. Journal of Advanced Mechanical Design, Systems, and Manufacturing 2010; 4(5): 1005-14 [https://doi.org/10.1299/jamdsm.4.1005]

[7] Aurich JC, Herzenstiel P, Sudermann H, Magg T. High-performance dry grinding using a grinding wheel with a defined grain pattern. CIRP Annals 2008; 57(1): 357-62 [https://doi.org/10.1016/j.cirp.2008.03.093]

[8] Denkena B, Grove T, Göttsching T. Grinding with patterned grinding wheels. CIRP Journal of Manufacturing Science and Technology 2015; 8: 12-21 [https://doi.org/10.1016/j.cirpj.2014.10.005 [9] Vesali A. Hochleistungs-
/Hochgeschwindigkeitsschleifen mit laserstrukturierten CBN-Schleifscheiben.
Freiburg: Albert-Ludwigs-Universität Freiburg 2015.

[10] Tönshoff HK, Hillmann-Apmann H, Asche J. Diamond tools in stone and civil engineering industry: cutting principles, wear and applications. Diamond and Related Materials 2002; 11(3-6): 736-41 [https://doi.org/10.1016/S09259635(01)00561-1]

[11] Turchetta S. Cutting Force in Stone Machining by Diamond Disk. Advances in Materials Science and Engineering 2010; 2010: 1-6 [https://doi.org/10.1155/2010/631437]

[12] Denkena B, Grove T, Göttsching T. Noch schneller als Drehen. WB Werkstatt + Betrieb 2017; (3): 68-71.

[13] Shi Z, Malkin S. An Investigation of Grinding with Electroplated CBN Wheels. CIRP Annals 2003; 52(1): 267-70 [https://doi.org/10.1016/S00078506(07)60581-2]

[14] Zhao B, Jiang G, Ding W, et al. Characterisation of the wear properties of a single-aggregated cubic boron nitride grain during Ti-6Al-4V alloy grinding. Wear 2020; $\quad$ (452-453): $\quad 1-12$ [https://doi.org/10.1016/j.wear.2020.20329 6]

[15] Naskar A, Choudhary A, Paul S. Wear mechanism in high-speed superabrasive grinding of titanium alloy and its effect on surface integrity. Wear 2020; (462-463): $1-$ 13 [https://doi.org/10.1016/j.wear.2020.20347 5] 